\title{
PENGARUH SUHU BAHAN BAKAR TERHADAP KEPERLUAN BAHAN BAKAR PADA MOTOR DIESEL SATU SILINDER 20 HP DENGAN ELEKTROLISER
}

\author{
Sutomo, Murni, Rahmat \\ Program Studi Diploma III Teknik Mesin \\ Fakultas Teknik Universitas Diponegoro \\ wahyu_setiawati@ymail.com
}

\begin{abstract}
Sutomo, Murni, Rahmat, An internal combustion process of fuel will works effectively if the fuel's density and viscosity is lower so we would like to use a heater in order to decrease the density and viscosity of the fuel. Based on this condition, we would like to use an electrolizer and a diesel engine to improve the fuel consumption. Electrolizer will increases the gas reaction so we hope that fuel consumption rate will decrease. The result of this research is the effective temperature of fuel is $50^{\circ} \mathrm{C}-60^{\circ} \mathrm{C}$ will produce the effective combustion. The fuel consumption decreased in $6 \mathrm{~kW}$ is $0.12 \mathrm{lt} / \mathrm{kWH}$.
\end{abstract}

Key word: diesel engine, electrolizer, temperature

\section{PENDAHULUAN}

Mutu penyalaan adalah salah satu sifat yang penting dari bahan bakar diesel. Mutu penyalaan bahan bakar tidak hanya menentukan mudahnya penyalaan dan penstateran mesin dingin tetapi juga jenis pembakaran yang diperoleh dari bahan bakar. Bahan bakar dengan mutu penyalaan yang baik akan memberikan mutu operasi mesin yang lebih halus, kurang bising terutama mencolok pada beban ringan.

Mutu penyalaan diukur dengan indeks yang disebut bilangan setana. Mesin diesel kecepatan tinggi memerlukan bilangan setana sekitar 50. Nilai dari bilangan ini sebagai karakteristik bahan bakan diesel adalah serupa dengan bilangan oktan pada bensin. Bilangan bahan bakar adalah persen volume dari setana dalam campuran setana dan alfa-metilnaftalen yang mempunyai mutu penyalaan sama dengan bahan bakar yang diuji.

Untuk menunjukkan tingkat kepekaannya terhadap detonasi, setana normal $\left(\mathrm{C}_{16} \mathrm{H}_{36}\right)$ dan alfamethyl-naphthalene $\left(\mathrm{C}_{10} \mathrm{H}_{7} \mathrm{CH}_{3}\right)$ dipergunakan sebagai bahan bakar standar pengukur, berturutturut menunjukkan bahan bakar yang sukar dan mudah berdetonasi. Bahan bakar yang akan ditentukan bilangan utamanya itu diuji dengan sebuah mesin yang khusus dipakai untuk mengukur bilangan setana. Dalam hal ini, kelambatan penyalaan dipakai sebagai pembanding. Maka persen volume setana dalam campuran yang terdiri atas setana dan alpha-methyl-naphthalene, yang memberikan kelambatan penyalaan sama dengan bahan bakar yang diuji.

Dengan melakukan proses pemanasan bahan bakar diharapkan akan dapat meningkatkan proses pembakaran yang lebih sempurna karena viskositas dan densitasnya menurun sehingga memungkinkan proses injeksi pengkabutannya di dalam pembakaran dapat lebih baik dan tenaga yang dihasilkan akan meningkat.

\section{TINJAUAN PUSTAKA}

Perhitungan densitas dilakukan berdasarkan data hasil pengujian bahan bakar solar yang dipanaskan.

$\rho=\frac{\text { berat piknometer isi-berat piknometer kosong }}{\text { volume piknometer }}$

Keterangan :

$\rho:$ density $\left(\mathrm{kg} / \mathrm{m}^{3}\right)$

Perhitungan viskositas dilakukan berdasarkan data hasil pengujian bahan bakar solar yang dipanaskan, setelah density didapat kemudian kami hitung viskositasnya.

$G_{1} 1 /\left({ }_{1} 2=\left(d_{1} 1 . t_{1} 1\right) /\left(d_{1} 2 . t_{1} 2\right)\right.$

Keterangan :

$\eta_{1}:$ viskositas cairan yang dicari $\left(\mathrm{m}^{2} / \mathrm{dt}\right)$

$\eta_{2}$ : viskositas cairan pembanding $\left(\mathrm{m}^{2} / \mathrm{dt}\right)$

$\mathrm{d}_{1}$ : density cairan yang dicari ( $\left.\mathrm{gr} / \mathrm{ml}\right)$

$\mathrm{t}_{1}$ : waktu alir cairan yang dicari (detik)

$\mathrm{d}_{1}$ : density cairan pembanding ( $\left.\mathrm{gr} / \mathrm{ml}\right)$

$\mathrm{t}_{1}$ : waktu alir cairan pembanding (detik)

Perhitungan beban untuk menghitung beban sebenarnya yang digunakan pada saat pengambilan data adalah :

$$
\mathrm{Nb}=\frac{E . T}{e_{b}}
$$

Keterangan :

$\mathrm{Nb}$ : beban sebenarnya (kWatt)

$\mathrm{E}$ : tegangan listrik (volt)

I : arus listrik (ampere)

$\mathrm{e}_{\mathrm{b}}$ : efisiensi transmisi penggerak sabuk $=0.95$

\section{METODOLOGI}

Mutu penyalaan bahan bakar adalah salah satu sifat yang penting dari bahan bakar diesel. Bahan bakar dengan mutu penyalaan yang baik akan memberikan mutu operasional mesin menjadi 
lebih halus, kurang bising terutama mencolok pada beban kerja yang ringan.

Mesin diesel terdiri atas beberapa komponen /bagian yang mempunyai beberapa fungsi dan saling menunjang satu dengan yang lainnya. Adapun sistem penunjang yang dimaksud adalah: sistem bahan bakar pada mesin diesel, sistem pelumasan pada mesin diesel, sistem pendinginan pada mesin diesel. Dalam sistem bahan bakar, mutu penyalaan bahan bakar menentukan mudahnya penyalaan dan penstateran mesin dingin juga jenis pembakaran yang diperoleh dari bahan bakar.

Mutu penyalaan bahan bakar diukur dengan indeks yang disebut bilangan setana. Mesin diesel kecepatan tinggi memerlukan bilangan setana sekitar 50. Nilai dari bilangan ini sebagai karakteristik bahan bakan diesel adalah serupa dengan bilangan oktan pada bensin. Bilangan bahan bakar (bilangan setana) merupakan persen volume dari setana dalam campuran setana dan alfa-metilnaftalen yang mempunyai mutu penyalaan sama dengan bahan bakar yang diuji.

Senyawa hidrokarbon setana normal $\left(\mathrm{C}_{16} \mathrm{H}_{36}\right)$ dan alpha-methyl-naphthalene $\left(\mathrm{C}_{10} \mathrm{H}_{7} \mathrm{CH}_{3}\right)$ dipergunakan sebagai bahan bakar standar pengukur, berturut-turut menunjukkan bahan bakar yang sukar dan mudah berdetonasi. Bahan bakar yang akan ditentukan bilangan utamanya itu diuji dengan menggunakan sebuah mesin yang khusus dipakai untuk mengukur bilangan setana. Kelambatan penyalaan dipakai sebagai pembanding dalam penelitian ini. Maka persen volume setana dalam campuran yang terdiri atas setana dan alphamethyl-naphthalene, yang memberikan kelambatan penyalaan sama dengan bahan bakar yang diuji.

Bahan bakar yang diuji juga mendapatkan perlakuan khusus, pemanasan awal bahan bakar menggunakan heater / elektroliser. Dengan melakukan proses pemanasan bahan bakar diharapkan akan dapat meningkatkan proses pembakaran yang lebih sempurna karena viskositas dan densitas bahan bakar akan menurun, sehingga memungkinkan proses injeksi pengkabutannya dapat lebih baik di dalam proses pembakaran dan akan meningkatkan tenaga yang dihasilkan.

\section{PROSEDUR PENGAMBILAN DATA}

- Menghidupkan mesin diesel, menyalakan pemanas bahan bakar, menghidupkan eletroliser yang disalurkan ke accu 12 volt.

- Penempatan tabung kaca stainless diusahakan yang jauh dari sumber panas (exhaust knalpot). Jika tidak yakin, pasang alumunium foil sebagai penghalang panas.

- Penempatan tabung water traps pada posisi yang jauh dari sumber panas.

- Pemasangan PWM

o Kabel merah PWM dihubungkan ke elektroliser brown gas positif.

o Kabel hitam PWM dihubungkan dengan accu negatif.

o Kabel biru PWM dihubungkan dengan negatif tabung stainless elektroliser.

o Untuk penempatan elektrik PWM ditempatkan di tempat yang mudah dilihat supaya dapat mengontrol indikator tegangan ampere.

o Pertama kali penggantian disarankan indikator PWM menunjukkan pada angka 4-6 ampere.

o Bila indikator PWM telah menunjukkan angka mendekati 20 ampere segera matikan saklar. Berarti air dalam elektroliser sudah kotor dan segera ganti airnya.

o Pemasangan saklar di tempat yang mudah, sehingga elektroliser dapat dihidupkan dan dimatikan dengan mudah.

- Pengambilan data dimulai saat temperatur bahan bakar stabil.

- Membaca data dengan melihat temperatur bahan bakar dan waktu pemakaian bahan bakar untuk $100 \mathrm{ml}$.

- Pengambilan data dilakukan sebanyak 3 kali setiap pengujian.

- Setelah selesai matikan mesin diesel serta pemanas bahan bakar.

\section{HASIL DAN PEMBAHASAN}

Pemanasan bahan bakar dari $30^{\circ} \mathrm{C}$ sampai $70^{\circ} \mathrm{C}$ menunjukkan penurunan viskositas solar (terlihat dalam grafik 1) sehingga memungkinkan terjadinya proses pembakaran yang lebih sempurna

Tabel 1. Viskositas Solar yang Dipanaskan

\begin{tabular}{|c|c|c|c|c|c|c|}
\hline $\begin{array}{c}\text { Temperatur } \\
\left({ }^{\circ} \mathrm{C}\right)\end{array}$ & $\begin{array}{c}d_{1} \\
\left(\mathrm{~kg} / \mathrm{m}^{3}\right)\end{array}$ & $\begin{array}{c}\mathbf{t}_{1} \\
\text { (detik) }\end{array}$ & $\begin{array}{c}d_{2} \\
\left(\mathrm{~kg} / \mathrm{m}^{3}\right)\end{array}$ & $\begin{array}{c}\mathbf{t}_{2} \\
\text { (detik) }\end{array}$ & $\begin{array}{c}\eta_{2} \\
\left(\mathrm{~m}^{2} / \text { det }\right)\end{array}$ & $\begin{array}{c}\eta_{1} \\
\left(\mathrm{~m}^{2} / \mathrm{det}\right)\end{array}$ \\
\hline 30 & 842 & 29.58 & 995.68 & 8 & $7.98 \times 10^{-07}$ & $2.49519 \times 10^{-06}$ \\
\hline 40 & 830 & 29.15 & 992.25 & 8 & $6.53 \times 10^{-07}$ & $1.9903 \times 10^{-06}$ \\
\hline 50 & 822 & 26.55 & 988.07 & 8 & $5.47 \times 10^{-07}$ & $1.51024 \times 10^{-06}$ \\
\hline 60 & 816 & 24.35 & 983.24 & 8 & $4.67 \times 10^{-07}$ & $1.17966 \times 10^{-06}$ \\
\hline 70 & 804 & 23.97 & 977.81 & 8 & $4.04 \times 10^{-07}$ & $9.95316 \times 10^{-07}$ \\
\hline
\end{tabular}




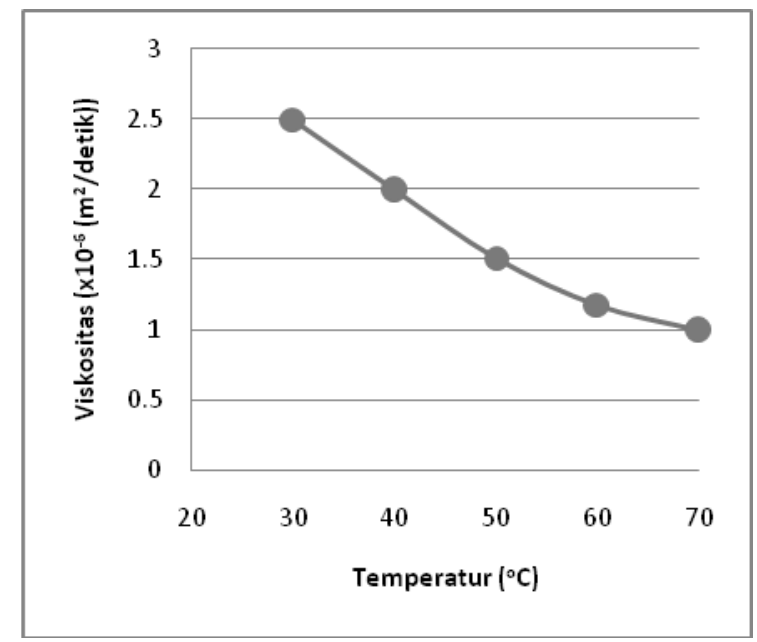

Grafik 1. Viskositas solar yang dipanaskan

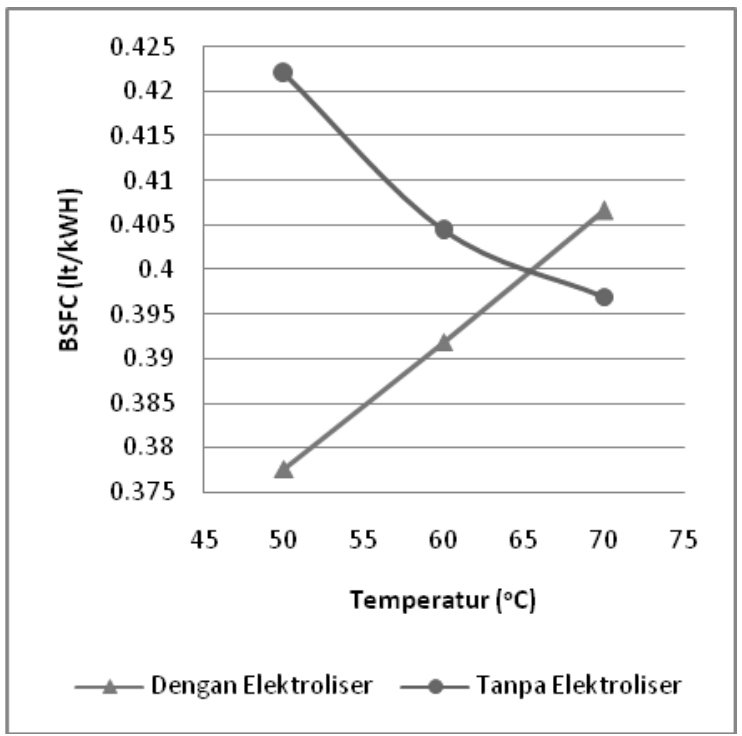

Grafik 2. Perbandingan BSFC antara menggunakan elektroliser dan tanpa elektroliser dengan beban $4 \mathrm{kWatt}$

Dari grafik 1 di atas, terlihat bahwa semakin tinggi temperatur maka semakin kecil kekentalan (viskositas) solar.

Pada beban 4 kWatt sesuai grafik 2, pemanasan bahan bakar efektif sampai suhu $65^{\circ} \mathrm{C}$ dapat meningkatkan penghematan bahan bakar dari $3-11.7 \%$. Sedangkan pada beban $5 \mathrm{kWatt}$, sesuai grafik 3, efektifitas bahan bakar 0.03 lt/kWH. Begitu pula dari grafik 4 untuk beban $6 \mathrm{kWatt}$, efektifitas pengaruh pemanasan terjadi pada suhu $50^{\circ}-55^{\circ} \mathrm{C}$

Dari pengamatan perubahan beban dan perubahan suhu dapat disimpulkan bahwa suhu efektif pemanasan adalah $50^{\circ}-55^{\circ} \mathrm{C}$ akan dapat meningkatkan penghematan bahan bakar 0.065 lt/kWH pada beban $6 \mathrm{kWatt}$ yang dilengkapi dengan elektroliser yang meningkatkan efektifitas pembakaran bahan bakar dengan menambahkan HHO produksi dari elektroliser.

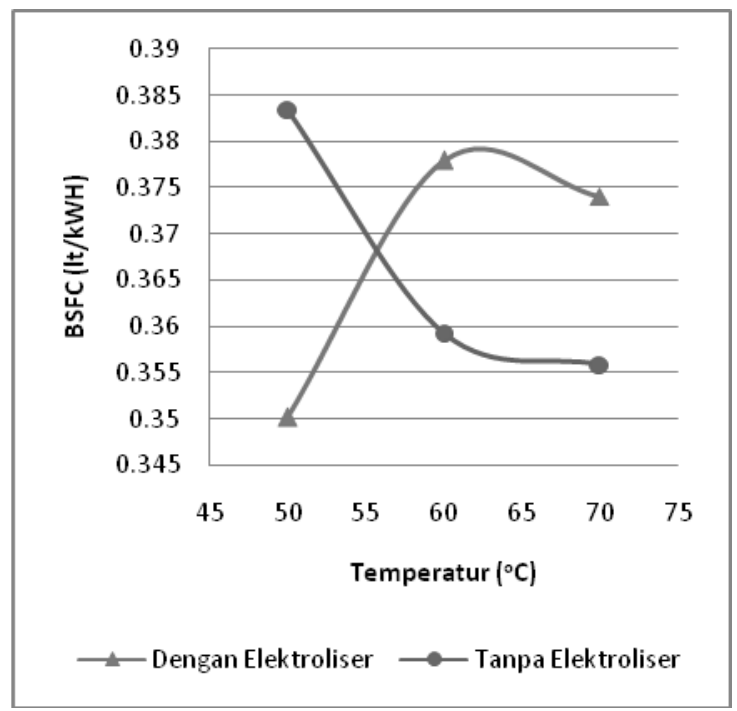

Grafik 3. Perbandingan BSFC antara menggunakan elektroliser dan tanpa elektroliser dengan beban 5 kWatt

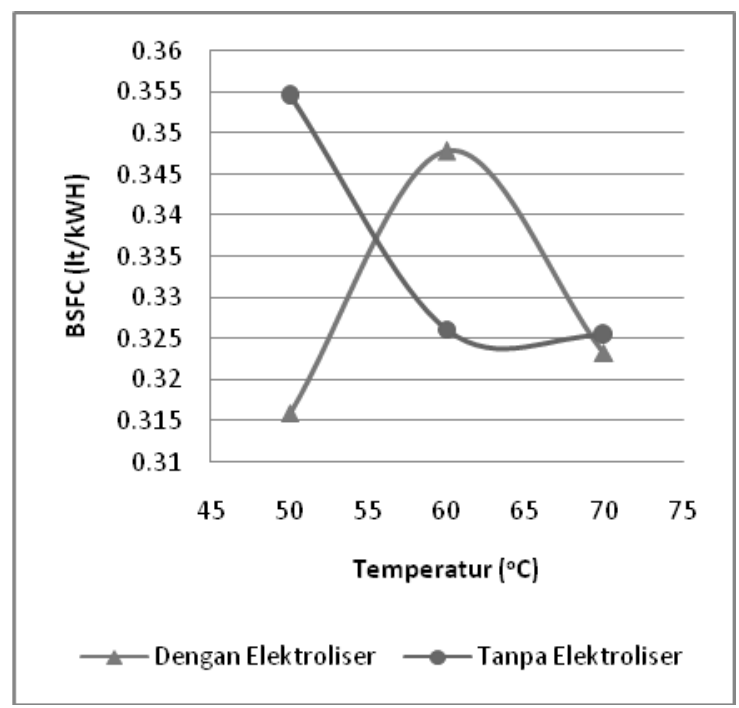

Grafik 4. Perbandingan BSFC antara menggunakan elektroliser dan tanpa elektroliser dengan beban 6 kWatt

\section{KESIMPULAN DAN SARAN}

Berdasarkan penelitian ini dapat disimpulkan sebagai berikut :

- Semakin tinggi temperatur pemanasan bahan bakar maka viskositas dan densitas bahan bakar akan semakin menurun yang akan memudahkan proses terjadinya pembakaran yang lebih sempurna.

- Efektifitas pemanasan terjadi pada suhu 50$55^{\circ} \mathrm{C}$ untuk beban $4 \mathrm{kWatt}$ sampai $6 \mathrm{kWatt}$. 
- Pada suhu bahan bakar $50^{\circ} \mathrm{C}$, beban $4 \mathrm{kWatt}$ penghematan pemakaian elektroliser dan heater dapat dicapai $0.041 \mathrm{lt} / \mathrm{kWH}$. Sedangkan untuk beban 5 kWatt, penghematan dicapai 0.034 lt/kWH. Sehingga untuk beban 6 kWatt lengkap dengan heater dan elektroliser dibandingkan dengan tanpa elektroliser, penghematan dicapai $0.12 \mathrm{lt} / \mathrm{kWH}$.

Berdasarkan hasil kesimpulan tersebut, disarankan supaya diteliti lebih lanjut mengapa pada suhu bahan bakar mendekati $70^{\circ} \mathrm{C}$ justru terjadi penurunan penghematan bahan bakar, yang dimungkinkan dinaikkan lagi dengan merubah waktu penyalaan pembakaran supaya dapat tepat terjadi pembakaran yang lebih sempurna lagi.

\section{DAFTAR PUSTAKA}

1. Arismunandar, Wiranto, dan Tsuda, Koichi. 2002. Motor Diesel Putan Tinggi. Jakarta : Pradya Paramita.

2. Hidayatullah, Poempida, dan Mustari, F. 2008. Rahasia Bahan Bakar Air. Jakarta : Cahaya Insan Suci.

3. Maleev, V.L. 1986. Operasi dan Pemeliharaan Mesin Diesel. Jakarta : Erlangga.

4. Manual Book. Diesel Engine Operation Manual.

5. Petrovsky, N. 1968. Marine Internal Combusting Engine. Moscow : Mir Publisher.

6. Sukardjo. 1989. Kimia Fisika. Yogyakarta : FPMIPA IKIP. 